\section{ON GALYL, A SUBSTITUTE FOR SALVARSAN AND NEOSALVARSAN.}

BY ARTHUR FOERSTER, M.R.C.S., L.R.C.P.LOND.,

CAPTAIN, ROYAL ARMY MEDICAL CORPS; LATE RESIDENT MEDICAL OFFICER, LONDON LOCK HOSPITAL.

6 OF late, arsenical compounds have gained a permanent and prominent foothold in the therapeutic arsenal of syphilis, so much so that any new arsenoorganic substance allied to salvarsan is apt to command attention. This consideration has led me to give a new and not generally known drug a trial. Moreover, a shortage of good salvarsan menaces us in the near future owing to the war, and thus it is highly desirable to find a reliable substitute. The importance of this matter has been pointed out quite recently by Mr. J. Ernest Lane, ${ }^{1}$ who has observed some alarming and grave accidents following upon the use of salvarsan of French and British manufacture.

The drug referred to in this paper is a discovery of Dr. Mouneyrat, to wholn we owe hectine, and is named Galyl (1116). Like salvarsan, it is a derivative of arsenobenzol, which was first prepared by Michaelis in 1881. In galyl two molecules of arsenobenzol are linked with two phosphoric groups; it is tetraoxy-diphospho-amino-diarsenobenzene, and corresponds to the following formula:-
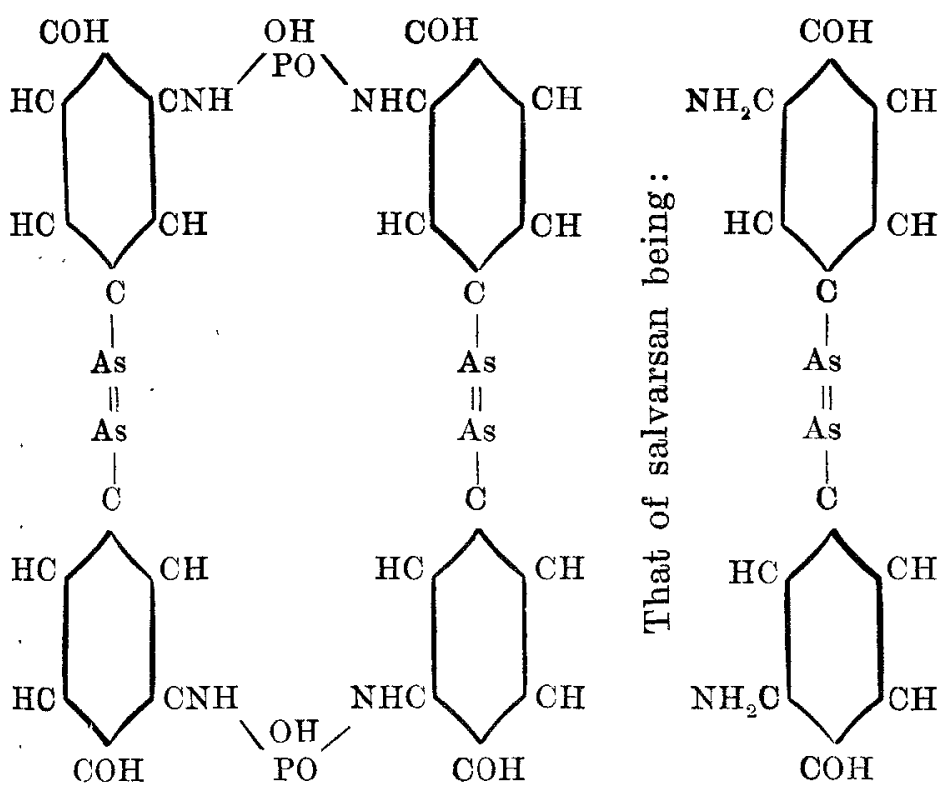

It contains 35.3 per cent. of arsenic and 7.2 per cent. of phosphorus, is a yellow powder of a tint different from those of salvarsan and neosalvarsan, and is insoluble in distilled water. It, however, dissolves rapidly in a weak solution of sodium carbonate, from which it can be precipitated readily by the addition of an acid. The tubes in which the drug is dispensed, contain the small amount of sodium carbonate required for solution, and thus the handling and dissolving are no more complicated than in the case of neosalvarsan. The solutions are yellow, with a brownish-green tint when fairly concentrated, and differ considerably from the bright yellow of salvarsan solutions.

Technique.-Galyl is best administered by means of intravenous injections, as intramuscular injections are painful and may lead to necrosis like salvarsan. Any of the methods used for the latter drug are admissible. Personally, I prefer the infusion method, as it gives the best guarantee against infiltration of the soft tissues, and fairly concentrated solutions seem to me to be better borne than weak dilutions-a view which also applies to salvarsan and neosalvarsan.

I have confined myself so far to using galyl on syphilitic cases with very pronounced lesions, partly because this procedure yields the most palpable and convincing evidence of the value of the drug, partly because patients with definite symptoms attend more regularly, and partly because no substitute for salvarsan can be accepted unless it has equal or almost equal curative properties.

CAsE 1.-Aged 26; infected Christmas, 1914. Sore on prepuce since middle of January, 1915. First seen on March 29th; indurated chancre occupied almost the entire circumference of the free margin of the prepuce, producing phimosis. Marked polyadenitis ; intense papular eruption on body and limbs. Patient complained of severe headache and sore-throat. Galyl, 0.4 grm., was given intravenously; no reaction. On April 6th the chancre was almost healed; the prepuce was becoming movable. The eruption was fading, notably on the limbs. The patient considered the improvement marvellous, and stated that the headaches had disappeared. A second injection of galyl, $0.5 \mathrm{grm}$., was given; this was followed by a reaction. On April 14th the patient was very well. The chancre had completely healed. The glands had gone down considerably, and the rash was merely indicated in a few places by pigmentation. As the patient was in the army he was advised to continue further: treatment under the care of his regimental doctor.

CASE 2.-Infected Christmas, 1914. On Feb. 8th, 1915; large chancre on penis, characteristic glandular enlargement in both groins, and a papular eruption on body, limbs, and face. On Feb. 10th intravenous injection of galyl, $0.4 \mathrm{grm}$.; no reaction. On Feb. 17th chancre was much smaller and undoubtedly healing. The papules on face and forehead had disappeared; those on the other parts were flat and fading. Galy], $0.5 \mathrm{grm}$, was given. On March $3 \mathrm{rd}$ further improvement. Only a few pigmented spots were left. The chancre had healed completely. Another injection of galyl, $0.5 \mathrm{grm}$., was given. On March 30 th the patient wrote from the country, "My health is perfect," and was advised to start upon a course of mercury.

CASE 3.-Aged 28 ; exposed himself to infection, Christmas, 1914, after having enlisted. Balanitis supervened, and sick leave was granted. On March 8th, 1915, horribly septic chancre; the glans was bathed in pus, eroded, hard, and painful. The patient was pale and weak, and complained of headache and sore-throat. Poly-micro-adenitis ; papular rash all over, in places rupial in character. Galyl, 0.4 grm., given intravenously. On March 16th penis no longer painful and healing well. The prepuce had become more movable. The rash was disappearing everywhere. The patient asked for another injection, and received $0.5 \mathrm{grm}$. of galyl ; marked reaction. Since then he has made further progress and returned to his regiment.

CASE 4.-Colonial soldier, infected Jan. 3rd, $1915 . \quad$ On March 9th typical Hunterian chancre, $4 \mathrm{~cm}$. long and $1.5 \mathrm{~cm}$. wide, running along the right half of the balanopreputial sulcus. Very marked glandular reaction in both groins. No other symptoms. An intravenous injection of galyl, 0.4 grm., was given; no reaction. The patient has. not been seen since, but he wrote on April 5th: "I mav say that $I$ am feeling $O . K$. and my shanker is all healed with the exception of a little spot, and same is drying very quickly." He also mentions in a postscriptum that he " had to walk 23 miles next day after having had his injection."

CASE 5.-Aged 28; infected mid-January, 1915. In the beginning of March he noticed a small pimple on his foreskin which became larger, and induced him to seek advice. On March 23rd ecthymatous chancre on prepuce, bubo in left groin, poly-micro-adenitis, and roseola. Galyl, $04 \mathrm{grm}$., was given intravenously; no reaction. On March $30 \mathrm{th}$ chancre healed, roseola disappeared; the bubo was nuch smaller, and the skin over it no longer red. Another injection of $0.4 \mathrm{grm}$. was given; no reaction. On April $6 \mathrm{~h} \mathrm{~h}$ the patient felt very well and was free from symptoms. $\mathrm{He}$ 
received another injection of $0.4 \mathrm{grm}$, which was followed almost immediately by sickness. He admitted having had breakfast only two hours previously. The patient has been well since, and has started upon mercurial treatment.

CASE 6.-Aged 29; exposed himself to infection in the middle of January, 1915, and noticed a small sore two weeks later at the left side of the root of the penis. This gradually increased in size; loss of appetite, headaches, and a rash supervened. On March 29 th the patient sought advice; flat chancre at left side of penis where it joins the body; inguinal glands characteristic. The glans penis was studded with typical mucous plaques. The body was covered with a macular rash, and the throat was injected. Galyl, 0.3 grm., was given intravenously. On April 6th the chancre, which was of the size of a shilling, was almost healed. The mucous plaques on the glans and the rash had disappeared. Galyl, 0.4 grm., was injected. On April 13th the chancre was healed completely. The patient had an acute attack of g jnorrhcea, and measures were adopted accordingly.

CaSE 7.-Aged 23 ; complained since middle of January, 1915, of hoarseness and pain in the throat. As " he could not understand it" he consulted a doctor, who prescribed local treatment and mercury pills. When first seen on Feb. 8ih no rash was present and no chancre could be found on the genitals. The anterior half of the tongue showed two typical mucous plaques, and another larger one was present at the labial commissure. Typical laryngitis. On Feb. 10th galyl, 0.4 grm., was injected intravenously. On Feb. 17th the patient, who was "better and stronger every day," was able to work again. All the lesions had healed and the voice was almost normal again. An injection of $0.4 \mathrm{grm}$. was given. On March 3rd another injection of $0.5 \mathrm{grm}$. was administered. The voice was normal. On April 13th the patient returned from the country very fit, and was advised to undergo mercurial treatment.

CASE 8.-Aged 27; acquired syphilis Christmas, 1912. He developed in due course a chancre, a papular rash, and mucous plaques in the buccal cavity, for which he was treated in London. He received two injections of salvarsan given at 14 days' interval, and bi-weekly injections of mercury for six weeks. Since the end of 1914 he had been suffering from a recurrence. An eruption broke out on his forehead, forming an unsightly placard $2.5 \mathrm{in}$. wide and 2 in. high. On March 23rd, 1915, large papulo-tubercular syphilide on forehead, extending from the eyebrows to the hair of the scalp; no other lesion. Galyl, $0.4 \mathrm{grm}$. , was given intravenously. On March 29th the eruption was practically cured. The skin was evenly flat and smooth, though somewhat redder than the intact surface. The patient was enthusiastic and asked for another injection. $0.5 \mathrm{grm}$. was given, and this was followed by a marked reaction. On April 5th he wrote to say that he was well and asked for further advice.

CASE 9.-Aged 49; acquired syphilis in 1885. His chancre was cauterised and a course of mercurial pills was followed for three months. The patient claimed to have remained well till 1902, when he developed psoriasis. The * lesions were at the time successfully removed. Since October, 1914, the psoriasis had shown itself again. - On March 9th, 1915, the patient, a prematurely old man, was very worried, and unemployable owing to the condition of his hands and face. No sign of tabes. The wrists, elbows, thighs, buttocks, \&c., were covered with typical lesions, some as large as a florin. The crusts were especially marked at the elbows. There was a certain amount of itching. Galyl, $0.3 \mathrm{grm}$., was given intravenously; no reaction. On March 16th no definite improvement; the patient claimed that the irritation had subsided ; 0.4 grm. was given. On March 23rd again no definite result; injections of enesol were given, and the patient was advised to use his chrysarobin ointment again. On April 15th marked improvement.

Therapeutic results.-In considering the results obtained in the above series the last case may be excluded. This patient had been suffering for a long time from genuine psoriasis which had come on many years after he contracted syphilis. Here no symptomatic cure was effected. The patient holds that his health has been improved, and that the irritation has subsided. Thus a small success may possibly be claimed. However, as in the case of salvarsan and neosalvarsan, the beneficial effect of galyl upon psoriasis must be con. sidered doubtful. Some lesions may clear up, others do not.

In every one of the other cases the results have been excellent. An immediate-from the very next day on, as one patient remarkedimprovement followed upon the administration of galyl, and all the lesions disappeared within a very short time. As Case 4 shows, one injection is quite sufficient to heal a very large chancre, and mucous plaques heal in a few days (Cases 6 and 7). All secondary rashes respond well and quickly. The effect upon the general health is that of a tonic.

Salvarsan, whether employed intravenously or intramuscularly, does not yield any better results. With equal dosage they would be inferior. Even when I compare the results given by the first (experimental) tubes of salvarsan (606 $\mathrm{Hy}$ ) with those obtained by galyl, I am unable to find any superiority for the German drug. Being one of those who had occasion to handle salvarsan before it became common property, and having used it ever since, I may be permitted to state that I am decidedly under the impression that the salvarsan sold of late by the German manufacturers is much less potent than the experimental tubes given out by Ehrlich in the beginning, and neosalrarsan is weaker still. Galyl appears to me to be superior to both salvarsan and neosalvarsan with regard to its symptomatic effect upon primary and secondary lesions. This is a considerable advantage, as these lesions are the most virulent and dangerous, and require a rapid cure owing to the risks they imply for the community.

With neosalvarsan galyl shares its solubility, which has made the former so popular.

Ill-effects.-All my cases were injected under unfavourable conditions. Most of them had to come up by omnibus or train and returned imme. diately, or in less than two hours, to their homes. There can be no doubt that the ill-effects could be reduced, or even excluded, if the patients were injected in a nursing home or hospital and were kept under observation.

Yomiting was noted once (Case 5) after the third injection. The patient brought up egg and other matter and confessed to having had breakfast only two hours previously. The vomiting in this instance was self-inflicted, and would certainly also have occurred had salvarsan or neosalvarsan been used.

With the doses $0.3 \mathrm{grm}$. and $0.4 \mathrm{grm}$. no ill-effects were observed. With $0.5 \mathrm{grm}$. the following took place in Cases 1,3 , and 8 , and this seems to be the only drawback worth considering. Almost immediately after the injection the patient becomes flushed and slightly dyspnoic. This is rapidly followed by pallor. The pulse becomes small and almost imperceptible, varying between 100 and 120. As the heart beats become feeble the limbs become numb and cold. In one instance pain in the stomach was complained of. These phenomena, however, pass off very quickly, and in none of $m y$ cases was there the slightest reason for alarm. Some people being more susceptible than others, all risks can be aroided by starting with small doses, excluding patients suffering from heart trouble, and allowing an 
interval of more than eight days between the injections. The vascular disturbance itself could be treated by means of intragluteal injections of adrenalin, as recommended by Milian for salvarsan disturbances, or, as I should prefer, by means of a hypodermic injection of ether, if deemed necessary.

Galyl is akin to salvarsan in its composition, and therefore headache, slight fever, diarrhœe, \&c., may occasionally be noticed. These accidents are trivial and require no special comment.

Dosage.-The "therapia sterilisans magna" so bombastically proclaimed by Ehrlich and his followers was never taken seriously by the judicious, and the events have shown its futility. It would be unfair to the drug and to the patients were one to expect from a single injection of galyl a complete cure, and not to take advantage of the lessons taught by the experience with salvarsan. In my opinion massive doses are to be deprecated. In the case of salvarsan they have given rise to more trouble than all the organic and inorganic "water faults" (Wechselmann, Emery) and other factors discovered by Ehrlich's partisans. Salvarsan poisoning is a serious matter, and there are, unfortunately, but few cases that come early enough to be aborted. In most cases a chronic intermittent treatment is indicated as in former days. What has changed is the detail. Making use of the various remedies, tests, \&c., at one's disposal, each case has to be treated according to its merits. The most rational procedure appears to me to consist in the removal of the urgent symptoms by means of a few injections of galyl, starting with $0.3 \mathrm{grm}$. in the case of adult males, and $0.2 \mathrm{grm}$. in the case of females, and following this up with mercurial treatment. A rest is then given, and the treatment resumed in due course, guided by the serum reaction, and carried out as required in each individual case.

I am well aware that various important questions connected with the drug, such as its effect upon tertiary lesions, its influence upon the serum reaction, \&c., require investigation, and that a great deal of further experience is necessary before a definite opinion can be formed on the merits and demerits of galyl. My clinical results, however, have been so encouraging, and I have seen most virulent syphilitic lesions heal so rapidly under its infiuence, that others may wish to give it a trial. As far as I can tell at this stage galyl appears to be "every bit as good" as salvarsan, and it is to be hoped that it may be tested more extensively.

Considering its price it may prove a blessing to military hospitals, infirmaries, and other large institutions.

Gloucester-place, $\mathbf{w}$.

The Mrgical and Swimming Baths of TORQUAP. - At the last meeting of the Torquay Borough Council it was reported that the baths would be completed by the end of October, by which date the committee hope to have an efficient staff ready.

The late Mr. Sam Cunliffe.-Mr. Cunliffe died at his residence, Witton Park, co. Durham, on August 31st, in his fortieth year. He was a native of Bolton and had lived in the Witton Park district since 1905. Greatly interested in municipal affairs, he contested the West Auckland district in two county council elections, and was successful in 1913. He was chairman of the Escomb parish council for many years, medical officer under the Auckland rural council, and a medical referee for the Durham Miners' Association, a public career which made him a very well-known man in his district.

\section{A CASE OF TEMPORARY MOTOR APHASIA DEVELOPING IN THE COURSE OF TUBERCULOSIS.}

By JOHN B. McDOUGALL, M.B., Ch.B. GLAsG., RTSIDENT MEDICAL OFFICER, STANFIELD SANATORIUM, BURSLEIF; ASSISTANT TUBERCULOSIS OFFICER, COUNTY BOROUGH OF STOKE-ON-TRENT.

SINCE the time when Broca made the discovery of localising the motor speech centre the cortical areas of the brain have been considered by most physiologists and physicians to represent the cerebral centres for our speech mechanism. It has been a misfortune, however, that much discrepancy of opinion has existed on this subject. No one area has been allowed to go unchallenged, and Marie has gone so far as to locate the entire speech mechanism to his "Wernicke's zone," which is supposed to occupy the left temporo-parietal lobe. Modern opinion, however, has become accustomed to the views of Broca, Dax and Moutier, and in this article the more commonly accepted localities in the cortex of the brain have been in the writer's mind.

For a proper understanding of the symptom. atology of aphasia it is necessary to remember that the entire speech mechanism is dependent on intellect. The greater the intellectual capacities of an individual the more extensive and the more complicated does the mechanism become, and the compass involved in the acquisition of foreign languages, music, mathematics, \&c., goes to. show that the sensory part of the receptive system is capable of almost unlimited development. Each new mental accomplishment requires, as it were, a new centre for its establishment.

Up to school age most children are in possession of two centres at least, an auditory speech centre and a motor speech centre. The former, which is placed in the first (and second) temporal con. volutions, is where all memories of sounds are stored; the latter is situated in the third left frontal convolution-i.e., Broca's convolution. 'This latter centre has for its function the outward expression of stored memories. During school life there are other two centres brought into action, but for their growth and efficiency it is necessary that the integrity of the auditory speech centre and the motor speech centre should be main. tained. The first of these centres, the visual speech centre, is said to be in the supramarginal convolution, and here resides the power which enables the child to understand written or printed language. Under the influence of this visual speech centre, when sufficiently developed, the writing centre is built up. There has been considerable discussion as to the exact site of the writing centre. Some have doubted its indepen. dent existence and have incorporated it with Broca's area. It is usually described, however, as being in the second left frontal convolution, and it is therefore possible for agraphia to exist alone as the sole symptom of a cortical lesion. F. Sans ${ }^{1}$ has reported a case of agraphia persisting alone after motor aphasia. It is very seldom that a lesion is confined to one particular part of the cortex and so gives rise to a purely typical aphasic syndrome. It is more common for the lesion to be, diffuse and to involve two or more of the 1 F. Sans: Revista de Medicina y Cirurgia Practicas, June 21st, 1914. 